\title{
The formal and informal surgical ethics curriculum: views of resident and staff surgeons in Toronto.
}

\author{
Frazer Howard \\ University of Toronto \\ Martin F. McKneally \\ University of Toronto \\ Ross E.G. Upshur \\ University of Toronto
}

Alex V. Levin

Wills Eye Institute, Thomas Jefferson University

Follow this and additional works at: https://jdc.jefferson.edu/willsfp

Part of the Surgery Commons

Let us know how access to this document benefits you

\section{Recommended Citation}

Howard, Frazer; McKneally, Martin F.; Upshur, Ross E.G.; and Levin, Alex V., "The formal and informal surgical ethics curriculum: views of resident and staff surgeons in Toronto." (2012). Wills Eye Hospital Papers. Paper 13.

https://jdc.jefferson.edu/willsfp/13

This Article is brought to you for free and open access by the Jefferson Digital Commons. The Jefferson Digital Commons is a service of Thomas Jefferson University's Center for Teaching and Learning (CTL). The Commons is a showcase for Jefferson books and journals, peer-reviewed scholarly publications, unique historical collections from the University archives, and teaching tools. The Jefferson Digital Commons allows researchers and interested readers anywhere in the world to learn about and keep up to date with Jefferson scholarship. This article has been accepted for inclusion in Wills Eye Hospital Papers by an authorized administrator of the Jefferson Digital Commons. For more information, please contact: JeffersonDigitalCommons@jefferson.edu. 


\title{
As submitted to:
}

\section{American Journal of Surgery}

\author{
And later published as:
}

\section{The formal and informal surgical ethics curriculum: views of resident and staff surgeons in Toronto}

\section{Volume 203, Issue 2, February 2012, Pages 258-265}

\section{DOI: 10.1016/j.amjsurg.2011.02.008}

\author{
Frazer Howard, M.Ed. , Martin F. McKneally, M.D., Ph.D., F.A.C.S., \\ F.R.C.S.C. ${ }^{\text {a,b, }}{ }^{*}$, Ross E.G. Upshur, M.D., M.A., F.R.C.P.C. ${ }^{\text {a,c }}$, Alex V. Levin, M.D., \\ M.H.Sc., F.R.C.S.C. \\ Joint Centre for Bioethics, Department of Surgery, and Primary Care Research Unit, \\ University of Toronto, Toronto, ON, Canada; Pediatric Ophthalmology and Ocular \\ Genetics, Wills Eye Institute, Thomas Jefferson University, Philadelphia, PA, US
}

\section{KEYWORDS:}

Bioethics; Residency; Curricula; Education

\begin{abstract}
BACKGROUND: Understanding what staff surgeons think surgical trainees should learn and the ethical issues that trainees need to manage can strengthen surgical ethics education.
\end{abstract}

METHODS: Participants were recruited from the 15 surgical specialty and subspecialty programs at the University of Toronto. Semistructured interviews and focus groups were conducted with 13 ethics coordinators from the surgical staff and 64 resident trainees. Data were analyzed qualitatively using modified thematic analysis.

RESULTS: All coordinators and trainees felt that ethics education was an important component of surgical training. Real cases, varying teaching methods, and teachers with 
applicable clinical experience were valued. Trainees identified intraprofessional and interprofessional conflict, staff behavior perceived to be unethical, and their own lack of experience as challenging issues rarely addressed in the formal ethics curriculum.

CONCLUSIONS: Ethics education is highly valued by trainees and teachers. Some ethical issues important to trainees are underrepresented in the formal curriculum. Staff surgeons and senior residents are practicing ethicists and role models whose impact on the moral development of residents is profound. Their participation in the formal curriculum helps less experienced junior residents realize its value. (C) 2012 Elsevier Inc. All rights reserved.

The case: It is July, and David Junior is a first-year resident working with senior staff general surgeon Dr Grey. David recently attended the departmental ethics session for residents on informed consent, a didactic lecture from the hospital's bioethicist. Dr Grey asks David to obtain consent for a laparoscopic cholecystectomy. David has seen the procedure once. He feels uncomfortable, because he does not have a nuanced understanding of the technical details and potential complications of the procedure. He does not feel he can describe the procedure well, but he does not want to displease his supervisor or lose the chance to assist on the case.

Conflicting expectations and needs can leave the resident, staff surgeon, and patient in the gap between the formal and informal ethics curricula. The surgeon thinks the resident is competent to obtain consent because he has had some formal instruction. The resident wants to learn how to manage the difficult task of presenting himself, a relative novice, in a way that is reassuring and helpful to a potentially frightened patient and provide what is needed for an informed decision. This is a poignant and common ethical dilemma for trainees: an incomplete match between what they were taught in the formal curriculum and the challenges they experience in daily professional life. If the curriculum addresses only what staff surgeons think surgical trainees need to learn, then the issues the trainees need to manage may be neglected.

An earlier study by University of Toronto medical students revealed ethical quandaries students faced that were not addressed in their formal ethics curriculum. Understanding this gap helped improve undergraduate medical ethics education. We undertook our study to provide the basis for improving the surgical component of the postgraduate ethics education program at the University of Toronto.

Much of the focus on postgraduate ethics education has been on defining effectiveness in terms of improvements on specific measures such as knowledge, ${ }_{5,8}^{3,4}$ ability to recognize ethical issues, attitudes and beliefs, and changes in behavior. ${ }_{9}^{4,8}$ None of these studies have dealt with surgical specialties. Hafferty and Franks and Hundert et al developed a taxonomy of ethics curricula that describes 3 overlapping spheres: (1) formal curricula: what is taught in the classroom; 
(2)informal curricula: unscripted, adhoc interpersonal lessons about values and attitudes, learned from role-models and peers outside the classroom as a subset of the hidden curricula; and

(3) hidden curricula: the sum of all the socializing influences imbedded in the organizational and institutional culture including tacit knowledge, or task-specific experiences that cannot easily be articulated or stored in documents.

Qualitative research is well suited to help us understand social phenomena in natural settings, giving due emphasis to the meanings, experiences, and views of all the

participants. ${ }^{11}$ Our study used qualitative methodology with focus groups and interviews of postgraduate teachers and trainees to provide an in-depth description of how both groups perceive the pathways to learn ethics in surgical residency.

\section{Methods}

\section{Sampling}

Participants were recruited from the surgical specialty and subspecialty programs at the University of Toronto (Table1).An outline of the research proposal was circulated by email to each surgical division head and the residency program directors. An e-mail invitation was sent to all surgical trainees indicating that participation in the study was voluntary and confidential, interviews and focus groups would be audiotaped and transcribed, and identifying information would not be included in the compiled data. This message was repeated at monthly intervals.

\section{Resident participants}

We conducted semi-structured interviews with 12 individual trainees ( 7 women) and 4 focus groups with a total of 52 trainees (9women) from cardiac surgery, plastic surgery, general surgery, surgical oncology, orthopedic surgery, otolaryngology, neurosurgery, pediatric general surgery, vascular surgery, urology, and obstetrics and gynecology. The focus groups ranged in size from 4 to 21 participants. Trainees ranged from first-year residents to senior subspecialty fellows (Fig. 1). The trainee focus groups were arranged with the assistance of program directors for academic half-days. Program directors and other faculty

Members were not notified which trainees participated in the study.

\section{Ethics coordinator participants}

Each of the surgical programs has a designated ethics coordinator who was contacted initially by e-mail. These coordinators are staff surgeons charged with the responsibility of facilitating ethics teaching in their programs. Surgical program chiefs were not notified 
of the ethics coordinators' involvement, and all collected data were de-identified.

We conducted individual interviews with ethics coordinators from 13 surgical residency programs. All coordinators are specialty-specific surgeons with an interest in ethics and recognized skill as teachers. Four of the coordinators were graduates of the master of health science in bioethics program at the University of Toronto Joint Centre for Bioethics; 5 have at some time worked on research ethics boards, ethics committees, or ethics-related educational activities; and4areresidencyprogramdirectorswhoassumed the role of ethics coordinator with no formal training in ethics. The participants had been ethics coordinators for periods ranging from 1 to 10 years.

\section{Data collection}

Interview guides (Appendices A and B) were used to structure both individual interviews and focus groups; they were developed on the basis of relevant literature and previous research. As is customary in qualitative research, the guides served as starting points and were revised during the course of the study to explore emerging themes.

Interviews with ethics coordinators were conducted by the research assistant (F.H.) in their respective offices. Trainee interviews were conducted by the research assistant at the trainee's in-hospital office or the office of the research assistant. The trainee focus groups were moderated by one of the co-investigators (M.F.M., A.V.L.) or by the research assistant, who took field notes for the focus groups when audio recording was impractical because of size of the group.

Interviews lasted 15 to 90 minutes. Focus groups lasted 45 to 120 minutes. Light snacks and beverages were provided at the focus groups, and the resident interviewees were paid $\$ 25$ for their participation. There were otherwise no financial, material, or academic incentives for participation. The interviews were transcribed by the research assistant and then entered into qualitative analysis software (Nvivo7; QSR International, Doncaster, Australia). Data collection continued until there was agreement among the research team that no new themes were emerging.

\section{Data analysis}

Data analysis used a modified thematic analysis involving 3 phases: open, axial, and selective coding. The first phase identified chunks of data that related to a concept (eg, trainee uncertainty), the second organized similar concepts into conceptual categories (eg, learning needs), and in the third, core categories emerged as the central themes of the study (eg, issues not addressed).

Thevalidityofourfindingswasaddressedin4ways.First, we corroborated data from different sources (interviews and focus groups). Second, a team consisting of the principal investigator (A.V.L.), a co-investigator (R.E.G.U.), and the research assistant independently reviewed randomly selected interviews and participated in the development of the coding framework. Third, all members of the research team enhanced the reflexivity (internal 
consistency) of the analysis by becoming familiar with all the data at regular conferences of the research team and participating in the data analysis. Fourth, all research activities were rigorously documented to permit a critical appraisal of the methods.

The project was approved by the research ethics boards of the University of Toronto and The Hospital for Sick Children.

\section{Results}

In addition to useful observations about the methods used to teach ethics and evaluate ethics teaching and learning, 3 major conceptual themes emerged in the interviews: (1)ethics education is important and valued,(2) some issues troubling to residents are not addressed in their ethics education, and (3) authentic voices, both clinical and ethical, are important for effective teaching.

\section{Formal ethics teaching}

Participants indicated that all of their programs had formal teaching sessions in ethics, although content, timing, teachers, and methods varied. Eight formal 1.5-hour ethics sessions are attended by junior residents from all surgical specialties in the first 2 years of training as part of their weekly Principles of Surgery lecture series. These lectures are interactive case-based large group discussions based on the Royal College of Surgeons of Canada bioethics curriculum. They address conflict of interest, doctor-patient relationship, end of life, innovation and research, religious and cultural issues, resource allocation, surgical competence, and truth telling. In addition, each surgical specialty program is required to provide specialty-specific ethics seminars for trainees during the academic year (Table 1). The number of hours, formality, and content of ethics training provided varies widely. Neurosurgery and pediatric general surgery have implemented curricula designed by their respective ethics coordinators during their studies in the master of health science in bioethics program.

The majority (11 of 13) of surgical programs use case-based small-group discussion as a primary format. Other formats used for teaching ethics include journal clubs (5 of 13), role playing (5 of 13), standardized patients ( 3 of 13), and debate (2 of 13). Purely didactic lectures were described by all as unhelpful. The coordinators in most ( 9 of 13) of the programs have led some of the in-class teaching sessions, although nearly all (12 of 13) indicated that they invite guest speakers to lead or co-teach for particular topics.

Most ethics coordinators ( 8 of 13) indicated that they used their own experience as surgeons to guide topic selection. Consultation with other faculty members and residents was also a common practice ( 8 of 13), but 2 coordinators pointed out that the trainees "don't know what they don't know." Many (6 of 13) enlisted the assistance of one of the investigators (M.F.M. or A.V.L.) to help choose and present appropriate subject matter. 
One coordinator picked topics from ethical issues that were a focus of current media and public interest. Topics addressed by coordinators in their ethics teaching sessions included specialty-specific examples of subjects addressed in Principles of Surgery lectures, plus advertising, assisted-reproduction technologies, consent, cosmetic surgery, errors, genetics, and medico-legal issues.

Current formal methods used to evaluate resident ethical behavior and knowledge are the in-training evaluation reports, objective structured clinical examination (OSCEs), and the Royal College of Physicians and Surgeons of Canada CanMEDS evaluation of professionalism.

\section{What is working}

All coordinators and trainees felt that ethics education was an important component of surgical training. Most trainees found ethics education relevant to their clinical experience. Even early exposure, less appreciated at the time, proves useful later. For example, 1 resident told us, "I remember the first year . .. people were rolling their eyes ... 'why don't they teach us clinical stuff'. .. but[now] they can speak more effectively in terms of using the terminology ... so they come back the second year with experiences that they can articulate."

Role models were identified among the faculty members and senior residents, who provided helpful guidance on how to handle ethical problems. Trainees and faculty members both felt that ethics is best taught through real cases. In 1 focus group, the residents described "bringing scenarios that we actually encountered and then we could discuss issues around them....It was great at bringing out issues."

The opportunity to step outside the clinical setting to discuss the issues and hear opinions from their peers and supervisors was highly valued. They believed that formal teaching is best done by someone with applicable clinical experience, though not necessarily from the same specialty. One coordinator said, "It's nice to have someone from outside of the division come and be like a third eye, be a third party....it changes the dynamics of the discussion. When you have somebody who's outside, the residents might be more forthcoming."

Varying teaching methods were successfully explored. Role playing, OSCEs, and debates were the main alternatives to small-group case discussion. A coordinator "had them actually role play, and then I had the rest of the residents comment or interject what they would do. It worked well." A resident agreed: "I actually think [an OSCE is] a much better teaching method ... putting yourself in the scenarios, actually dealing with a difficult situation, is something else. I think it was good."

Moving the sessions out of the usual academic teaching environment served to enhance this difference and allowed for more informal and open interaction. According to 1 
coordinator, "[Residents] told me that they appreciate the difference....Not[just] that they're at my house and Igive them something to eat, but that they are away from their regular place ... in the hospital seminar room ... you can't really relax in that environment."

\section{Challenges in learning ethics}

The residents were asked to identify the ethical issues they dealt with in their work and assess whether their training helped them. Frequent topics were consent, disclosure, end of life, surgical competence, and decision-making. Some residents felt that though these were covered in the formal curriculum, they still felt insufficiently prepared when facing them in practice. Many junior residents felt that forma lethics sessions were not relevant to them, as they had never had to cope with ethically challenging situations. In contrast, senior residents said it was not until they had to face an ethical problem that they realized the importance of ethics training. In 1 focus group, some junior residents thought "ethics training [was] a waste of time. It was ...out of context, starting way back then." Others responded: "It's so much more in context now when you're going through it and you feel, oh yeah, that has happened to me." 
Residents identified their own lack of experience, intra-professional and interprofessional conflict, and perceived unethical staff behavior as challenging issues for them that were rarely addressed in their formal curricula. Many residents felt powerless to influence patient care, even though they were the front-line care providers, because of decisions made further up the training hierarchy. They wanted to do what they felt was best for patients but were unsure of what steps they could take, and they ultimately felt that the surgical staff was responsible. "You're thinking. ..this guy needs an operation. Because the surgeon didn't come in to do it...[the patient] ended up in a nursing home for the rest of his life.... Who do you talk to about that? ... you talk to the other surgeons, and they say 'well, he was the guy on call.' .. . you don't know if this is .. . an isolated incident, or is this something regular that this guy does? ... It makes you angry in a way, but you can't really do much about it, you just have to watch it unfold." "And the problem is, especially when you're a [first-year resident], there's no system in place sometimes to say, just help me."

Residents felt that discussing ethics issues is not well developed as part of the culture of surgical practice. Ethical issues may be raised, but much more importance is given to surgical aspects of cases. Many residents felt the staff members need ethics training as well as the residents. "Staff should ...notice cases where an ethical concern exists and challenge the residents ... does anyone think we should have done anything different? ... that generally doesn't happen....The discussion around ethics ... is rarely there."

Most residents felt that ethics evaluation methods were insufficient. "It's difficult to evaluate, especially because it's very rare that a surgeon or any doctor really observes the resident in any interaction [involving ethical issues with patients]." All felt that feedback on how they handle ethically difficult situations in clinical practice would help them identify areas where they need to improve, much like other surgical skills. "If you just let people slide by ... it's not their fault. If you tell them there's a problem and you help them to get better skills, they generally get better."

\section{Challenges in teaching ethics}

The coordinators felt that junior residents believed that an ethical issue would not pose as much difficulty for them as an unfamiliar surgical situation and that ethics questions were unlikely to appear on a certification examination, so they would prefer to focus on content more likely to appear on the examination. "They're not so afraid of how to deal with an ethically difficult situation...they're afraid of being in the middle of the night with some sort of surgical catastrophe and they have no clue what to do." "Ethics is an area which a lot of them are quite aware is not really on their exam."

Although the coordinators with formal ethics training were confident teaching ethics, those with less training felt less comfortable. "[It's] a leap for them to think of themselves as being competent to talk about it....They can talk about their experiences and how they would take it from their own personal perspective.... [formal] ethics is one of those things that we're just not sure about." 
All respondents felt that ethics teaching is most successful when it gives residents practical insight into the issues they face with in their particular specialties. Residents would like to hear staff experience with these issues and learn how staff surgeons coped with them. Residents and coordinators felt that teachers who are "in the trenches with them" are better able to engage the trainees and reinforce the idea that ethics is connected to their work. Coordinators believed that residents "need that ethical framework, and it's got to be reinforced by daily recognition with the residents so they see it every day in practice." "I think that's what anchors it and what makes it relevant.... Talking to them about ... the principles of justice and that kind of thing . . . [is] like forcing them to listen to [public broadcasting]."

All respondents identified role modeling and day-to-day interaction with staff members as the most influential aspects of training. Both groups noted that there were both positive and negative examples to follow or avoid. Residents felt that they must navigate among their teachers and use their own judgment in identifying appropriate behaviors. The coordinators concurred with this, and some felt that "bad" role models can provide as valuable a learning experience as "good" role models. The residents wanted these sensitive issues discussed: "We see staff members whose personal and family lives are falling apart, and what kind of a role model for the future is that for us? We can see that happening because of the time they are spending at work and it seems like there's no other way around it, but is that really how it should be? ... Does that mean to be a surgeon means that you cannot have a normal, healthy life? These are ethical issues no one really talks about. We've never had that discussion in the classroom." Coordinators agreed: "Being prepared to talk about these delicate issues is really important for staff. Talking about errors, talking about cases with iffy indications for surgery, talking about all these tough ethical dimensions of our work . ..are really important for the residents."

\section{Comments}

In an earlier study, many chief residents (27 of 34) told us that "ethics is as important as my clinical training." described and instructor-described learning needs in the operating room. ${ }^{13}$ Our study used in-depth individual interviews and focus groups to explore the formal, informal, and hidden aspects of ethics education in surgical training. Residents and staff physicians have complementary views regarding effective ethics teaching. Faculty members and trainees agree on the optimal methods for teaching, such as clinical case discussions, and identify the usefulness of clinically experienced ethics teachers. 
Our findings confirm that although ethics training is valued, there is a gap between what is formally taught and what trainees need to know to manage the ethical issues they encounter. Residents felt that the formal ethics curricula did not address some issues that they identified as most challenging. In response, we continue to modify the content of our curriculum. Although junior trainees recognized the need for ethics teaching, many described feeling insufficiently prepared to manage the ethical issues they faced. Over time, they will develop the required crystallized intelligence, composed of knowledge, experience, and judgment, that cannot be imparted in lectures alone.

As in many discussions of ethics with residents, these interviews brought out some problems that caused social distress rather than moral distress. Concerns about social interactions across authority gradients and the family life of overworking role models are not addressed in the formal ethics curriculum. Residents were disturbed that there was no outlet for them to have the behavior of negative role models addressed. These problems are usually aired among the trainees themselves, without the presence of mentors. A route for open discussion and intervention needs to be explored, such as confidential discussions with program directors and ethics teachers or routes for anonymous feedback. Paradoxically, negative surgical role models can be used to illuminate and reinforce surgical virtues.

Coordinators were aware that junior residents early in their training were less motivated to learn about ethics than explicit surgical knowledge. Although the Toronto Principles of Surgery examination does include questions on ethics issues, the national examination does not. A change in this policy will strengthen motivation to learn. Senior residents, often through unplanned experience, encounter and learn to resolve ethical quandaries and come to value the relevant formal and informal education they have received. The reflections of senior residents harmonize with Aristotle's advice that ethics teaching is wasted on the young, who have insufficient life experience to appreciate its value. ${ }^{14}$ Yet residents at all levels valued their ethics education, at least in retrospect.

One of the foundational principles of the University of Toronto ethics education in residency initiatives is that effective teachers should be able to speak with an authentic voice based on knowledge, skill, and judgment within their specialties. In general, the ethics coordinators are chosen for their ability as teachers and the level of respect they have earned from residents. Given that surgery is a specialty rich in opportunities to exercise judgment on the basis of ethical values and norms, the ethics coordinators are able to hold the interest of their residents and lead them toward understanding ethical issues in surgery by emphasizing judgment.

We have tried to address the coordinators" need for ethics training through a "hub and spokes" model of postgraduate faculty ethics education. Ethics coordinators are provided with access to educational resources online (http:// www.utoronto.ca/pgme/), through group educational activitiessuchas"teachingtheteachers"seminars, accesstoethicists for advice and co-teaching, and the opportunity to obtain an master of health science in bioethics degree in a professional part-time program (http://www.jointcentreforbioethics.ca/ 
education/mhsc.shtml).

Evaluation of trainee behavior needs strengthening. Much excellent work has been accomplished in this field in other domains of medical education. ${ }^{15,16}$ Surgical residents are rarely observed or evaluated when they are doing histories and physical examinations, talking to patients about ethical issues, or discussing the risks and gains of surgical treatment. It is unusual for a senior surgeon to observe a resident in any interaction with patients other than performing operations or procedures.

\section{The way forward}

Critical analysis and feedback from the study participants has improved our approach to teaching surgical ethics. The intended goals of formal ethics training are clarified by learners and teachers working together, addressing questions such as why and how we should be teaching and what we should be learning. Curriculum developers can capitalize on ethical issues trainees are confronting in their practice and create opportunities for them to develop personal ethical frameworks to identify, understand, and deal with those issues. Surgeons teaching ethics can look to their own past experience during training and their current role for guidance on how best to address these issues. Surgeonteachers acknowledged informal interaction as the dominant educational influence, though many felt underprepared to influence the behaviors and beliefs of their residents. There are excellent opportunities in surgical practice to strengthen informal ethics teaching by example. Junior residents are rarely present during attending surgeons' discussions with patients and families about the risks, uncertainties, and benefits of surgical treatment, or their empathetic explanations of unexpected complications or deaths related to surgery. They are more often dispatched to deal with preparation of the next case or address management issues on the surgical floor. Surgeons can be reminded of these opportunities to serve as role models and mentors. They are the most effective teachers of surgical ethics.

Emphasis can be placed on providing trainees with a low-risk environment to learn how to cope with authentic and relevant ethical issues. Just as the surgical skills laboratory improves technique and self-confidence while maintaining trainee interest, ${ }^{18,19}$ skills at managing ethical problems might be strengthened by demonstrations with standardized

patients, interviews with volunteer patients reflecting authentically on their own health care experiences, and observed discussions of informed consent, complications, prognoses, and errors.

The case that introduced this report illustrates the moral distress of a junior resident expected to conduct a consent interview alone and unobserved, on the basis of a formal ethics lecture. He is underprepared by experience and training to manage the discussion confidently. His respected staff surgeon should observe Dr Junior struggling to explain a laparoscopic cholecystectomy to an anxious patient. In the tradition well developed over centuries of surgical training in the operating room, Dr Grey would immediately recognize the signs of an understandable lack of experience in his subordinate and intervene to 
help. He would teach by example, demonstrating expertise in the performance of a fundamental transaction in surgical ethics.

\section{Limitations}

The trainee group was self-selected and may have been biased toward the views of those who are interested in ethics or dissatisfied with their training. Our findings are from a single institution. Although efforts were made to enroll subjects from each surgical specialty, our sample may not be representative of the ethics learning needs and challenges of all surgical trainees.

\section{Conclusions}

Ethics education is highly valued by trainees and teachers. Some ethical issues important to trainees are underrepresented in the formal curriculum. We learned from this study that staff surgeons and senior residents are practicing ethicists and role models whose impact on the moral development of residents is profound. Their attendance and participation as co-teachers in the formal curriculum - answering questions and giving examples from their practice - has helped place our ethics sessions among the most valued in the teaching program. Their effectiveness can be strengthened by participation in ethics education. We are encouraged to find that an increasing number of staff surgeons, residents, and fellows have chosen to study surgical ethics formally.

\section{Acknowledgments}

We would like to acknowledge the assistance of Drs Robert Mustard, Christopher Wallace, Ian Witterick, and Ted Gerstle in arranging focus groups. We especially thank all the faculty members and residents who participated in this project. We would also like to acknowledge the assistance of Shawn Tracy, Kasia Gogol, Monica Branigan, Michelle Zeller, Roderick Cheung, Erik Venos, Theresa Pazionis, and Joseph Koval in the development of qualitative modalities and techniques. An earlier version of this paper was improved by insightful comments and suggestions from 2 anonymous reviewers and Deborah McKneally.

\section{References}

1. Hicks LK, Lin Y, Robertson DW, et al. Understanding the clinical dilemmas that shape medical students' ethical development: questionnaire survey and focus 
group study. BMJ 2001;322:709-10.

2. Howard F, McKneally MF, Levin AV. Integrating bioethics into postgraduate medical education: the University of Toronto model. Acad Med 2010;85:103540.

3. Howe KR, Jones MS. Techniques for evaluating student performance in a preclinical medical ethics course. J Med Educ 1984;59:350-2.

4. Sulmasy DP, Geller G, Levine DM, et al. Medical house officers' knowledge, attitudes, and confidence regarding medical ethics. Arch Intern Med 1990;150:2509-13.

5. Hebert PC, Meslin EM, Dunn EV. Measuring the ethical sensitivity of medical students: a study at the University of Toronto. J Med Ethics 1992;18:142-7.

6. Smith SR, Balint JA, Krause KC, et al. Performance-based assessment of moral reasoning and ethical judgment among medical students. Acad Med 1994;69:3816.

7. Sulmasy DP, Geller G, Levine DM, et al. A randomized trial of ethics education for medical house officers. J Med Ethics 1993;19:157-63.

8. Shorr AF, Hayes RP, Finnerty JF. The effect of a class in medical ethics on firstyear medical students. Acad Med 1994;69:998-1000.

9. 9. Hafferty FW, Franks R. The hidden curriculum, ethics teaching, and the structure of medical education. Acad Med 1994;69:861-71. 
10. Hundert EM, Hafferty F, Christakis D. Characteristics of the informal curriculum and trainees' ethical choices. Acad Med 1996;71:624-42.

11. Mays N, Pope C. Rigour and qualitative research. BMJ 1995;311: 109-12.

12. Levin AV, Berry S, Kassardjian CD, Howard F, McKneally MF. "Ethics teaching is as important as my clinical education": a survey of participants in residency education at a single university. UTMJ 2006; 84:60-3.

13. Pugh CM, DaRosa DA, Glenn D, et al. A comparison of faculty and resident perception of resident learning needs in the operating room. J Surg Educ 2007;64:250-5.

14. Aristotle. Nicomachean ethics. I.iii. 5-8. Ross WD, trans. Constitutional Society, Library of Constitutional Classics.

15. Jefferies A, Simmons B, Tabak D, et al. Using an objective structured clinical examination (OSCE) to assess multiple physician competencies in postgraduate training. Med Teach 2007;29:183-91.

16. Ginsburg S, Regehr G, Hatala R, et al. Context, conflict, and resolution: a new conceptual framework for evaluating professionalism. Acad Med 2000;75:S6-11.

17. McKneally MF, Singer PA. Bioethics for clinicians: 25. Teaching bioethics in the clinical setting. CMAJ 2001;164:1163-7.

18. Peyre SE, Peyre CG, Sullivan ME, et al. A surgical skills elective can improve student confidence prior to internship. J Surg Res 2006;133: 11-5. 
19. QayumiAK,CheifetzRE,ForwardAD,etal.Teachingandevaluation of basic surgical techniques: the University of British Columbia experience. J Invest Surg 1999;12:341-50.

20. Barrows HS. An overview of the uses of standardized patients for teaching and evaluating clinical skills. Acad Med 1993;68:443-51.

21. 21. Stern DT, Cohen JJ, Bruder A, et al. Teaching humanism. Perspect Biol Med 2008;51:495-507.

Appendix A Resident question guide

\begin{tabular}{|l|l|}
\hline Ethical issuesfaced & $\begin{array}{l}\text { Tell me about the ethical issues you face } \\
\text { most often as (a) resident(s). }\end{array}$ \\
\hline Where teaching happens & $\begin{array}{l}\text { Describe how you learn the most about } \\
\text { these types of issues. }\end{array}$ \\
\hline $\begin{array}{l}\text { What is taught compared with what is } \\
\text { faced at work }\end{array}$ & $\begin{array}{l}\text { How does what you have learned about } \\
\text { this ethical issue resonate with what } \\
\text { "really happens" during your clinical } \\
\text { experience? }\end{array}$ \\
\hline Evaluation & $\begin{array}{l}\text { Tell me about the evaluation of bioethics } \\
\text { teaching and learning in your program }\end{array}$ \\
\hline
\end{tabular}

Appendix B Bioethics coordinator question guide

\begin{tabular}{|l|l|}
\hline Topics taught & $\begin{array}{l}\text { Can you give me some examples of the } \\
\text { bioethics topics taught to the residents? } \\
\text { How are these topics chosen? }\end{array}$ \\
\hline Methods & In your experience, what are the most \\
\hline
\end{tabular}




\begin{tabular}{|l|l|}
\hline & $\begin{array}{l}\text { effective methods of teaching residents } \\
\text { about bioethics? }\end{array}$ \\
$\begin{array}{l}\text { In your view, what are the best settings } \\
\text { for teaching residents about bioethics? }\end{array}$ \\
\hline Evaluation & $\begin{array}{l}\text { Tell me about the evaluation of bioethics } \\
\text { teaching being done in your program. }\end{array}$ \\
\hline Overall & $\begin{array}{l}\text { Overall, what do you think has the most } \\
\text { influence on how residents learn about } \\
\text { and deal with ethical issues? }\end{array}$ \\
\hline
\end{tabular}

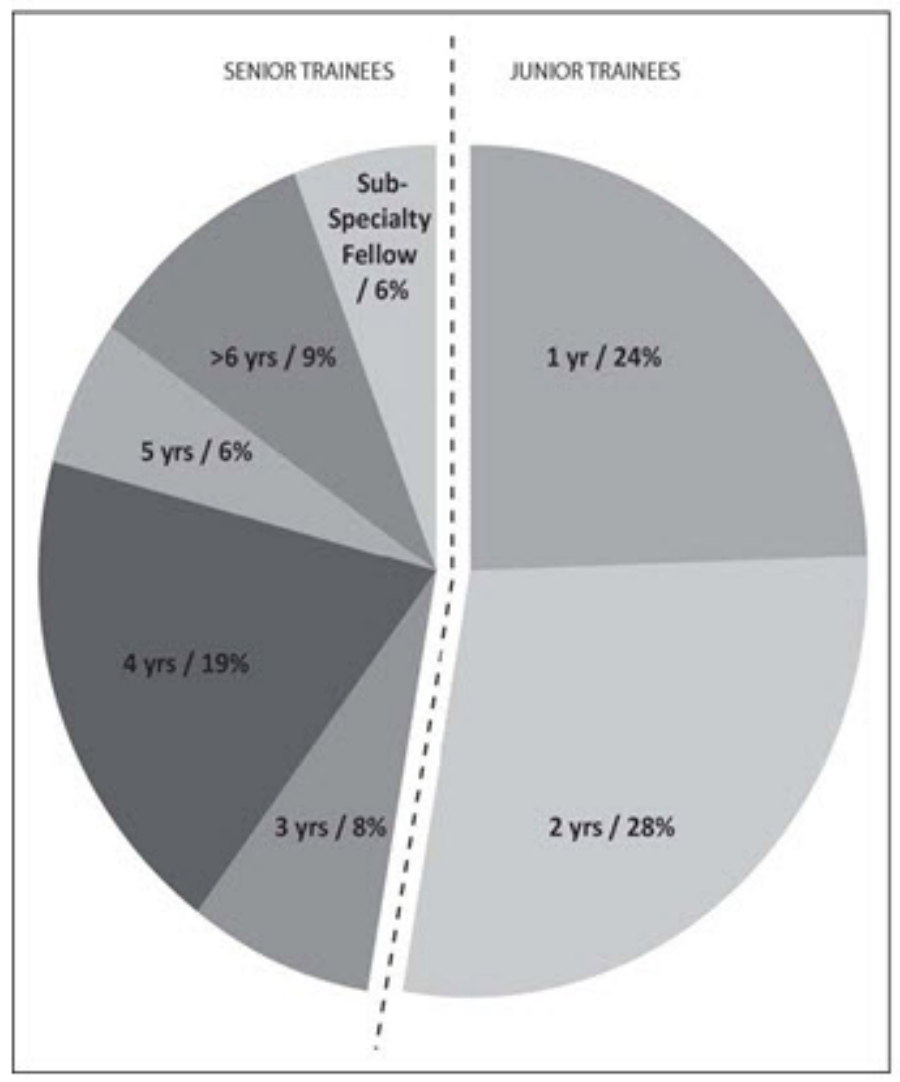

Figure 1 Number of years in residency/percentage of participants. 
Table 1 Surgical programs at the University of Toronto: number and duration of specialty-specific bioethics seminars**

\begin{tabular}{|c|c|c|c|}
\hline Surgical specialty & Trainees per year & Length (y) & Bioethics seminars (attendees) \\
\hline $\begin{array}{l}\text { Cardiac } \\
\text { General }\end{array}$ & $\begin{array}{l}2 \text { or } 3 \\
8-11\end{array}$ & $\begin{array}{l}6 \\
5\end{array}$ & $\begin{array}{l}\text { Three or four } 2 \mathrm{~h} \text { (all trainees) } \\
\text { Two } 2 \mathrm{~h} \text { (senior trainees) }\end{array}$ \\
\hline $\begin{array}{l}\text { Neurosurgery } \\
\text { Obstetrics and }\end{array}$ & $\begin{array}{l}3 \text { or } 4 \\
8\end{array}$ & $\begin{array}{l}6 \\
5\end{array}$ & $\begin{array}{l}\text { Three } 3 \mathrm{~h} \text { (all trainees) } \\
\text { Two } 2 \mathrm{~h} \text { (junior trainees), one or two } 3 \mathrm{~h} \text { (senior trainees) }\end{array}$ \\
\hline $\begin{array}{l}\text { gynecology } \\
\text { Ophthalmology }\end{array}$ & $4-6$ & 5 & $\begin{array}{l}\text { One } 2 \mathrm{~h} \text { (first-year trainees), } 1 \text { grand rounds } 2 \mathrm{~h} \text { (all + } \\
\text { staff), two } 2 \mathrm{~h} \text { (all trainees) }\end{array}$ \\
\hline Orthopedic & 10 & 5 & $\begin{array}{l}\text { Two or four } 1.5 \mathrm{~h} \text { (junior trainees), two or four } 1.5 \mathrm{~h} \\
\text { (senior trainees) }\end{array}$ \\
\hline Plastic & 2 & 5 & Three or four $2 \mathrm{~h}$ (senior trainees; juniors welcome) \\
\hline Urology & 4 & 5 & One $2 \mathrm{~h}$ (all trainees) \\
\hline Colorectal $^{*}$ & 1 or 2 & 2 & One $1 \mathrm{~h}$ (all trainees) \\
\hline Pediatric general* & 1 & 2 & Eight $3 \mathrm{~h}$ (all trainees) \\
\hline Surgical oncology* & 3 & 2 & Three $2 \mathrm{~h}$ (all trainees) \\
\hline Vascular* & 3 & 2 & One or two $1.5 \mathrm{~h}$ (all trainees) \\
\hline
\end{tabular}

* Subspecialtytraining following general surgery residency.

**These seminars supplement the ethics lectures given in the first 2 years of residency. 